\title{
Author Correction: Duplication of a domestication locus neutralized a cryptic variant that caused a breeding barrier in tomato
}

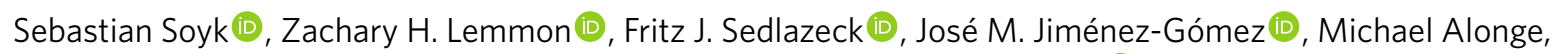
Samuel F. Hutton, Joyce Van Eck, Michael C. Schatz and Zachary B. Lippman (1)

Correction to: Nature Plants https://doi.org/10.1038/s41477-019-0422-z, published online 06 May 2019.

In the version of this Letter originally published, several in-text figure citations were written incorrectly: in the sentence beginning "To validate genetically that two..., "Fig. 3b" should have read "Fig. 3e"; in the sentence beginning "In a j2 mutant background...", "Fig. 3c" should have read "Fig. 3f"; in the sentence beginning "Quantitative differences in branching..." "Fig. 3d" should have read "Fig. 3g"; and in the sentence beginning "Importantly, higher EJ2 gene dosage..., "Fig. 3c,d" should have read "Fig. 3f,g". These errors have now been amended. 